\title{
Women experience a better long-term immune recovery and a better survival on HAART in Lao People's Democratic Republic
}

Mathieu Bastard ${ }^{1 *}$, Khamphang Soulinphumy ${ }^{2}$, Prasith Phimmasone ${ }^{3,4}$, Ahmed Hassani Saadani $^{5}$, Laura Ciaffi ${ }^{5}$, Arlette Communier ${ }^{5}$, Chansy Phimphachanh ${ }^{6}$, René Ecochard ${ }^{7,8,9}$ and Jean-François Etard ${ }^{1,10}$

\begin{abstract}
Background: In April 2003, Médecins Sans Frontières launched an HIV/AIDS programme to provide free HAART to HIV-infected patients in Laos. Although HIV prevalence is estimated as low in this country, it has been increasing in the last years. This work reports the first results of an observational cohort study and it aims to identify the principal determinants of the CD4 cells evolution and to assess mortality among patients on HAART.

Methods: We performed a retrospective database analysis on patients initiated on HAART between 2003 and 2009 (CD4<200cells/ $\mathrm{LL}$ or WHO stage 4). We excluded from the analysis patients who were less than 16 years old and pregnant women. To explore the determinants of the CD4 reconstitution, a linear mixed model was adjusted. To identify typical trajectories of the CD4 cells, a latent trajectory analysis was carried out. Finally, a Cox proportional-hazards model was used to reveal predictors of mortality on HAART including appointment delay greater than 1 day.

Results: A total of 1365 patients entered the programme and 913 (66.9\%) received an HAART with a median CD4 of 49 cells/ $\mu \mathrm{L}$ [IQR 15-148]. High baseline CD4 cell count and female gender were associated with a higher CD4 level over time. In addition, this gender difference increased over time. Two typical latent CD4 trajectories were revealed showing that $31 \%$ of women against $22 \%$ of men followed a high CD4 trajectory. In the long-term, women were more likely to attend appointments without delay. Mortality reached $6.2 \%(95 \% \mathrm{Cl} 4.8-8.0 \%)$ at 4 months and 9.1\% (95\% Cl 7.3-11.3\%) at 1 year. Female gender ( $\mathrm{HR}=0.17,95 \% \mathrm{Cl} 0.07-0.44)$ and high $\mathrm{CD} 4$ trajectory ( $H R=0.19,95 \% \mathrm{Cl} 0.08-0.47)$ were independently associated with a lower death rate.

Conclusions: Patients who initiated HAART were severely immunocompromised yielding to a high early mortality. In the long-term on HAART, women achieved a better CD4 cells reconstitution than men and were less likely to die. This study highlights important differences between men and women regarding response to HAART and medical care, and questions men's compliance to treatment.
\end{abstract}

\section{Background}

Highly active antiretroviral therapy (HAART) has clearly reduced morbidity and mortality of HIV-infected patients both in industrialized and developing countries [1-3]. The majority of HIV-infected people live in resourcepoor settings where programmes have been launched to provide free HAART. The efficacy and the feasibility of such programmes have been largely proved [4-6]. In

\footnotetext{
* Correspondence: mathieu.bastard@geneva.msf.org

'Epicentre, Paris, France

Full list of author information is available at the end of the article
}

2009, antiretroviral therapy coverage was estimated at 37\% in Sub-Saharan Africa and 31\% in East, South and Southeast Asia [7].

In Asia, the first case of AIDS was reported in 1984. The actual HIV prevalence is low but several countries show growing HIV epidemics [7,8]. In Lao People's Democratic Republic (Lao PDR), the first HIV infected patient was detected in 1990 but the HIV epidemiology is still not very well documented. The overall prevalence seems to have increased over the past years and is estimated at $0.2 \%$ [0.2; 0.4\%] in 2009 but this figure could be underestimated given the very few data available [7]. The

\section{Ciomed Central}


epidemic is largely driven by heterosexual transmission and cross-border migration is recognized as a key factor of the dynamic of the epidemic. Several studies and reports show a higher prevalence among men who have sex with men $(5.6 \%)$, female migrants $(0.8 \%)$ and service women $(0.4 \%)$ [9-12]. In order to prevent HIV infection, a $100 \%$ Condom Use Programme and the HIV/AIDS/STIs Plan for Lao PDR with twelve priority strategies have been developed [13,14].

In July 2001, Médecins Sans Frontières (MSF) opened a HIV/AIDS project in Savannakhet Provincial Hospital in Lao PDR to provide prophylaxis and treatment for opportunistic infections for HIV-infected patients. In April 2003, MSF started a programme of free antiretroviral distribution in Savannakhet Hospital which became at that time the only place in the country to provide HAART to HIV/AIDS-infected patients.

Several studies on cohorts of HIV-infected patients receiving HAART in Thailand and Cambodia have been published but to date, there is no equivalent publication on the outcomes of patients on-HAART in Lao PDR [15-20]. To fill this gap, we conducted a retrospective analysis on a database made available to us by the Ministry of health/ Center for HIV and STI and MSF in order to report the first results on patients receiving HAART at Savannakhet Provincial Hospital, located on the Thai-Lao border, between April 2003 and June 2009. This work aims at assessing immune recovery and survival of patients on HAART.

\section{Methods}

\section{Patients}

Patients included in this retrospective analysis entered the MoH-MSF programme of free HAART distribution between April 2003 and June 2009. We excluded from analysis patients who were less than 16 years old and pregnant women. Patients started on HAART if they met one of the following criteria: (1) CD4 cell count $<200$ cells $/ \mu \mathrm{L}$ irrespective of WHO clinical stage; (2) WHO clinical stage 4 irrespective of CD4 cell count. Date of HAART initiation for eligible patients ranged between September 2003 and June 2009.

Main initial regimens were triple-drug combinations made of two nucleoside reverse transcriptase inhibitor + one non-nucleoside reverse transcriptase inhibitor.

HIV testing, HAART, treatment of opportunistic infections (including tuberculosis), laboratory monitoring and transportations of patients were free of charge for eligible patients.

\section{Follow-up of the patients}

After a first visit at HAART initiation, patients were followed-up at week 2 and 4, and then, once a month at Savannakhet Provincial Hospital. After 6 months on HAART and if there were no complaints from the patients, the follow-up took place every 3 months. The CD4 cell count was monitored every 6 months, but no measurement of viral load was available. A paper-based system was used by the medical team to allow the clinical follow-up of the patients. Some key data on patients and follow-up were collected to produce activity reports using FUCHIA 1.6.1 software (Epicentre, Paris).

In October 2006, MSF opened a second treatment centre in capital Vientiane allowing the transfer of preHAART and on-HAART patients who originally lived in or around Vientiane. No information on patients transferred to Vientiane could be retrieved so they were censored at date of transfer. We considered a patient as lost to follow-up if their last visit preceded the closure date of the database by 6 months and if he was not dead and had not been transferred to Vientiane.

\section{Data analysis}

We performed a retrospective analysis on anonymized data, captured with Fuchia, made available to us by MoH-MSF. An internal unique key was generated by the system to link the patients' visits so that it was impossible to identify a patient. The database was locked on $30^{\text {th }}$ June 2009. The CD4 cell counts not available at HAART initiation $\left(D_{0}\right)$ were retrieved from 15 days before to 15 days after $\mathrm{D}_{0}$, and in a median time of 34 days before $\mathrm{D}_{0}$ for those with still missing CD4 cell count.

Baseline characteristics of men and women were compared using Fisher's exact test for categorical variables and Wilcoxon test for continuous variables.

We estimated the median progression of CD4 cells on HAART. We fitted a random-intercept linear mixed model for repeated measures using all available CD4 measurements at each time point to explore the effect of several characteristics of patients at HAART initiation: age, gender, Body mass index (BMI), WHO clinical stage, CD4 cell count and haemoglobin level. We also fitted a latent trajectory model, both for men and women, with a latent variable characterizing different patterns of CD4 cells over time [21]. This method aims at identifying typical latent trajectories of CD4 cells based on individual CD4 cells measures over time, as well as the prevalence of each latent trajectory. To model these trajectories, a polynomial function of time on HAART was considered. Then, we estimated, for each patient, a membership probability to each trajectory, and we assigned a unique trajectory to a patient by taking the maximum membership probability. Each patient has their own immune recovery over time, so it is important to underline that one typical trajectory does not describe entirely a given patient's CD4 evolution. This kind of analysis may be affected by the number of CD4 measurements over time per patient. To validate this approach, we have analyzed the membership probabilities according to the number of CD4 measurements for each patient. 
We also analyzed the punctuality of scheduled appointments, defined as attending the visit the exact scheduled day (or before), over time on HAART using mixed-effect logistic regression.

The participation time on HAART was calculated as the time between $D_{0}$ and the date of last visit, the date of transfer or the date of death. We described the mortality on HAART using Kaplan-Meier curves and log-rank tests. A Cox proportional-hazards model was adjusted to explore the link between typical latent CD4 trajectories and mortality, thus baseline CD4 count was not included because its effect was captured by the latent trajectories. Other possible risk factors at HAART initiation such as age, gender, Body mass index (BMI), WHO clinical stage and haemoglobin level were considered in the analysis. Punctuality of scheduled appointments was also investigated. Proportional hazards $(\mathrm{PH})$ assumption was checked by testing the Schoenfeld residuals. Because gender appeared to violate the $\mathrm{PH}$ assumption, time was split at 9 months and the effect of gender was thus estimated independently before and after 9 months on HAART.

Statistical analyses were performed with Stata 10.1 (Stata Corporation, College Station, Texas, USA) software using the generalized linear latent and mixed model (GLLAMM) framework [22].

\section{Ethical clearance}

This research followed the principles of the Helsinki Declaration, 2004 amendment and analysis plan was approved by the Ministry of Health - Centre for HIV, AIDS and STIs (MoH/CHAS) of Lao PDR which granted access to the anonymized data. This retrospective data analysis was performed on routinely collected data which were fully anonymized and involved no risk for participants. Verbal informed consent was obtained from patients during the first visit, and therefore, their first inclusion into the database.

\section{Results}

A total of 1365 patients were registered in the database. Among them, 3 were excluded because there were no data recorded for them and 134 were excluded because they were less than 16 years old. Before receiving HAART, 127 patients died, 30 were transferred to Vientiane and 71 were lost to follow-up. Among the 1000 patients alive and followed, 913 (91.3\%) were started on HAART and included in the analyses where as 87 were not initiated on ART because they were not eligible at the closing date of the database.

Patients' characteristics at HAART initiation are presented in Table 1. Median age was 32 years [interquartile range (IQR) 28-38] and 507 patients (55.6\%) were men. Majority of patients were at an advanced stage of HIV disease: 261 (28.6\%) with WHO stage 3 and 531 (58.2\%) with WHO stage 4 . The median baseline CD4 cell count was 49 cells/ $\mu \mathrm{L}$ [IQR 15-148] $(\mathrm{n}=775)$. Women had a significant higher CD4 cell count than men (median 65 vs. 41 cells $/ \mu \mathrm{L}, P=0.002)$. The median BMI $\left(18.5 \mathrm{~kg} / \mathrm{m}^{2}\right.$

Table 1 Patients' characteristics at HAART initiation, Savannakhet, Lao PDR, 2003-2009

\begin{tabular}{|c|c|c|c|c|}
\hline Characteristic $^{a}$ & Men $(\mathrm{N}=507)$ & Women $(\mathrm{N}=405)$ & $P$ & Overall $(\mathrm{N}=913)$ \\
\hline \multicolumn{5}{|l|}{ Age (years) } \\
\hline Median [IQR] & $33[29-38]$ & $32[27-37]$ & 0.003 & $32[28-38]$ \\
\hline \multicolumn{5}{|c|}{ WHO clinical stage } \\
\hline Stage 4 & $316(62.3 \%)$ & $215(53.1 \%)$ & $<0.001$ & $531(58.2 \%)$ \\
\hline Stage 3 & $143(28.2 \%)$ & $117(28.9 \%)$ & & $261(28.6 \%)$ \\
\hline Stage 2 & $35(6.9 \%)$ & $44(10.9 \%)$ & & $79(8.6 \%)$ \\
\hline Stage 1 & $13(2.6 \%)$ & $29(7.1 \%)$ & & $42(4.6 \%)$ \\
\hline \multicolumn{5}{|c|}{ CD4 cell count (cells/ $\mu \mathrm{L})^{b}$} \\
\hline Median [IQR] & $41[12-130]$ & $65[20-166]$ & 0.002 & $49[15-148]$ \\
\hline$<50$ & $236(55.3 \%)$ & $155(44.7 \%)$ & & $391(50.5 \%)$ \\
\hline 50-199 & $144(33.7 \%)$ & $133(38.3 \%)$ & & $278(35.9 \%)$ \\
\hline$\geq 200$ & $47(11.0 \%)$ & $59(17.0 \%)$ & & $106(13.6 \%)$ \\
\hline \multicolumn{5}{|c|}{ Body mass index $\left(\mathrm{kg} / \mathrm{m}^{2}\right)^{c}$} \\
\hline Median [IQR] & $18.7[17.1-20.7]$ & $18.2[16.4-20.5]$ & 0.07 & $18.5[16.8-20.6]$ \\
\hline \multicolumn{5}{|c|}{ Haemoglobin level $(g / d L){ }^{d}$} \\
\hline Median [IQR] & $11.6[9.9-13.2]$ & $11.3[9.6-12.7]$ & 0.07 & $11.4[9.7-13.1]$ \\
\hline
\end{tabular}


[IQR 16.8-20.6], $\mathrm{n}=904)$ and the median haemoglobin level (11.4 g/dL [IQR 9.7-13.1], $\mathrm{n}=530)$ did not strongly differ by gender $(P=0.07)$. The two main initial regimens were: stavudine/lamivudine/neviparine (Triomune ${ }^{\circledR}$ ) $(65.1 \%)$ and stavudine/lamivudine/efavirenz (33.1\%).

During HAART, the median CD4 cell gain increased strongly in the first year and attained +156 cells $/ \mu \mathrm{L}$ [IQR 104-231] at 12 months $(n=335)$. Then, it increased slowly from +191 cells/ $\mu \mathrm{L}$ [IQR $121-269$ ] at 18 months $(\mathrm{n}=336)$ to +294 cells/ $\mu \mathrm{L}$ [IQR $162.5-405]$ at 42 months $(\mathrm{n}=152)$ before stabilizing.

The results of the random-intercept linear mixed model are reported in Table 2. Patients with a higher baseline CD4 cell count achieved a higher long-term CD4 reconstitution, indeed patients with CD4 cell count between 50 and 199 cells $/ \mu \mathrm{L}$ (respectively more than 200 cells $/ \mu \mathrm{L}$ ) had on average +82 cells $/ \mu \mathrm{L}$ (respectively +194 cells $/ \mu \mathrm{L}$ ) more than patients with less than 50 cells $/ \mu \mathrm{L}$ at initiation after 2.5 years on HAART. However, the CD4 cells increased faster for patients with a lower baseline CD4 cell count (significant interaction between baseline CD4 cell count and time). Indeed, patients who had a baseline CD4 cell count $<50$ cells $/ \mu \mathrm{L}$ gained, on average per year, about +12 cells $/ \mu \mathrm{L}$ and +20 cells $/ \mu \mathrm{L}$ more than patients who had a baseline CD4 cell count between 50 and 199 cells $/ \mu \mathrm{L}$ and patients who had more than 200 cells/ $\mu \mathrm{L}$, respectively. In addition, after adjusting for baseline CD4 count, women had on average +38 cells $/ \mu \mathrm{L}$

Table 2 Predictors of CD4 reconstitution identified by the random-intercept linear mixed model $(\mathrm{N}=774)$,

Savannakhet, Lao PDR, 2003-2009

\begin{tabular}{|c|c|c|}
\hline Predictors & Coefficient & $95 \% \mathrm{Cl}$ \\
\hline \multicolumn{3}{|c|}{ Time since HAART initiation (year) $^{a}$} \\
\hline Linear trend & 25.15 & $(18.36 ; 31.93)^{*}$ \\
\hline Quadratic trend & -15.36 & $(-18.01 ;-12.71)^{*}$ \\
\hline Cubic trend & 6.48 & $(5.04 ; 7.92)^{*}$ \\
\hline \multicolumn{3}{|l|}{ Gender $^{b}$} \\
\hline Intercept & 38.54 & $(23.70 ; 53.38)^{*}$ \\
\hline Slope deviation & 14.82 & $(9.52 ; 20.12)^{*}$ \\
\hline \multicolumn{3}{|c|}{ CD4 at HAART initiation ${ }^{c}$} \\
\hline \multicolumn{3}{|l|}{ Intercept } \\
\hline 50-199 cells/ $\mu \mathrm{L}$ & 82.35 & $(66.74 ; 97.95)^{*}$ \\
\hline$\geq 200$ cells/ML & 194.42 & $(169.29 ; 219.55)^{*}$ \\
\hline \multicolumn{3}{|l|}{ Slope deviation } \\
\hline 50-199 cells/ $\mu \mathrm{L}$ & -11.64 & $(-17.12 ;-6.15)^{*}$ \\
\hline$\geq 200$ cells $/ \mu \mathrm{L}$ & -20.10 & $(-29.45 ;-10.74)^{*}$ \\
\hline
\end{tabular}

more than men after 2.5 years on HAART. Furthermore, the significant effect of the interaction term between gender and time indicated that women gained on average about +15 cells $/ \mu \mathrm{L}$ per year more than men. Finally, variance of the random-intercept represented about 35\% of the total variance $(\mathrm{p}<0.001)$, showing an important heterogeneity between patients.

The latent trajectory analysis reveals both for men and women two typical latent trajectories of CD4 cells over time (Figure 1). The first latent trajectory represented $78 \%$ of men and $69 \%$ of women, with a low CD4 trajectory, achieving about 300 cells/ $\mu \mathrm{L}$ after 60 months. The second latent trajectory represented $22 \%$ of men and $31 \%$ of women who experienced a high CD4 trajectory, reaching about 500 and 600 cells $/ \mu \mathrm{L}$ after 60 months for men and women, respectively. The average membership probability was about 0.8 for patients with a low number of CD4 measurements, and tended to 1 for patients with higher number of CD4 measurements.

Analysis of appointments revealed that $85.6 \%$ of visits took place without delay and that the median delay was 2 days [IQR 1-7]. A significant interaction between gender and time (in years) indicated a better punctuality of appointments for women compared to men in the longterm on HAART (Odds Ratio of interaction between gender and time: 1.09; 95\% CI 1.01-1.19).

The median participation time was 21.7 months [IQR 8.1-42.5] and the average interval between two visits was 1 month and 11 days. On HAART, 40 patients were lost to follow-up (4.4\%), 98 were transferred to Vientiane (10.7\%) and 107 died (11.7\%). Cumulative probability of

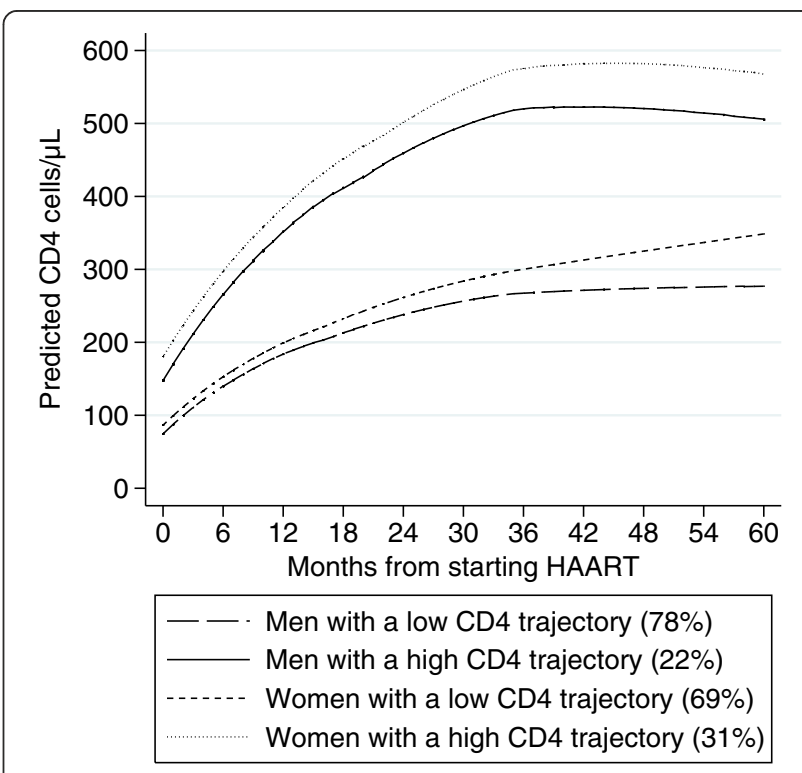

Figure 1 Latent CD4 trajectories for men and women on HAART, Savannakhet, Lao PDR, 2003-2009. 
being lost to follow-up on HAART was $2.42 \%$ (95\% CI $1.16-3.19 \%)$ at 12 months and 5.33\% (95\% CI 3.72-7.63\%) at 30 months. Kaplan-Meier estimates of mortality attained 6.2\% (95\% CI 4.8-8.0\%), 7.7\% (95\% CI 6.1-9.7\%) and $9.1 \%$ (95\% CI 7.3-11.3\%) at 4, 9 and 12 months, respectively. Mortality differed by the following factors: CD4 cell count (Figure 2a, log-rank test: $P=0.007$ ) and BMI (Figure 2b, log-rank test: $P<0.001$ ) at baseline, and by the typical latent $\mathrm{CD} 4$ trajectories (Figure 2c, logrank test: $P<0.001)$, showing a higher mortality among patients with a low CD4 trajectory. In addition, mortality seems higher for men after 9 months on HAART (Figure 2d), but due to the violation of the $\mathrm{PH}$ assumption, the log-rank test was not valid and we can not conclude of a significant difference. Following our analysis plan, baseline CD4 cell count was not included in the multivariate Cox model, which showed that a high CD4 trajectory over time (Hazard Ratio 0.19, 95\% CI 0.08-0.47), female gender after 9 months on HAART (HR 0.17, 95\% CI 0.07-0.44) and a baseline BMI $\geq 18 \mathrm{~kg} / \mathrm{m}^{2}$ (HR 0.39,

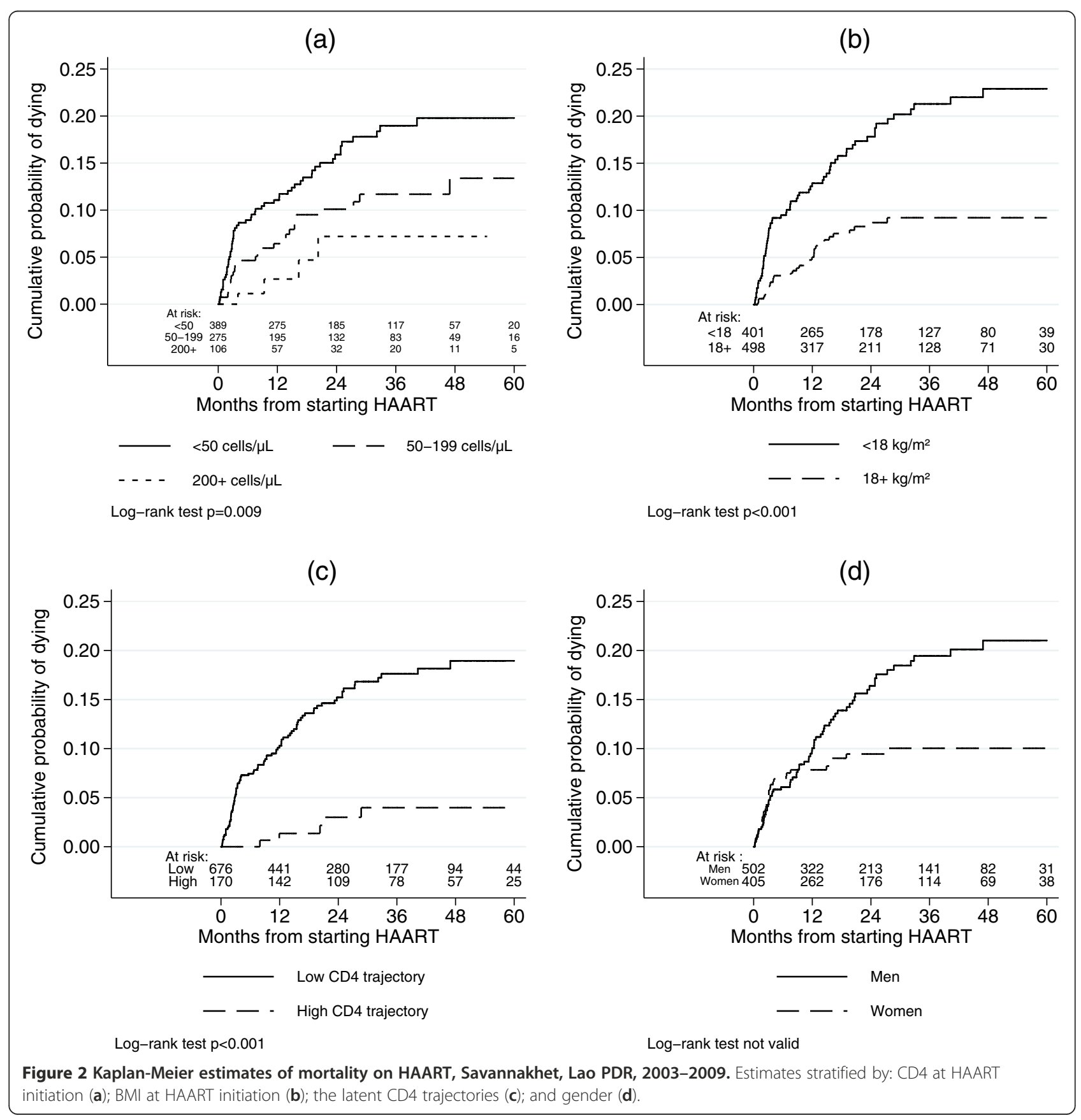


95\% CI 0.25-0.60) were independently associated with a lower death rate (Table 3). However, gender before 9 months on HAART and attendance to clinical appointments were not associated with mortality.

\section{Discussion}

Throughout this retrospective study, a better long-term immunologic reconstitution for women after HAART initiation was pointed out. Two typical latent trajectories of the CD4 cells for men and women were identified, showing that about $31 \%$ of women had a high CD4 trajectory against about $22 \%$ of men. In addition, a better survival was independently associated to female gender after 9 months and to patients with a high CD4 trajectory on HAART.

\section{Programme evaluation}

A recent bulletin of the World Health Organization (WHO) states that, on average, 21\% of the patients are lost to follow-up in the first 6 months after HAART initiation in resource-limited settings [23]. In Sub-Saharan Africa, a systematic review of HAART programmes shows that around $40 \%$ of patients were lost to follow-up after 2 years on HAART [24]. In addition, a recent metaanalysis of the mortality of patients LTFU in resourcelimited settings reveals that 20 to $60 \%$ of the patients LTFU have died [25]. The present analysis indicates a low lost to follow-up rate showing a good compliance to the programme. Moreover, the high frequency of the visits at the hospital (on average every 1 month and 11 days) underlines the good monitoring of the cohort.

\begin{tabular}{|c|c|c|c|}
\hline Predictors & HR & $95 \% \mathrm{Cl}$ & $P$ \\
\hline \multicolumn{4}{|c|}{ Latent CD4 trajectories } \\
\hline Low CD4 trajectory & 1 & & \\
\hline High CD4 trajectory & 0.19 & $(0.08 ; 0.47)$ & $<0.001$ \\
\hline \multicolumn{4}{|c|}{ Gender before 9 months on HAART } \\
\hline Men & 1 & & \\
\hline Women & 1.19 & $(0.69 ; 2.05)$ & 0.53 \\
\hline \multicolumn{4}{|c|}{ Gender after 9 months on HAART } \\
\hline Men & 1 & & \\
\hline Women & 0.17 & $(0.07 ; 0.44)$ & $<0.001$ \\
\hline \multicolumn{4}{|c|}{ BMI at HAART initiation } \\
\hline$<18 \mathrm{~kg} / \mathrm{m}^{2}$ & 1 & & \\
\hline$\geq 18 \mathrm{~kg} / \mathrm{m}^{2}$ & 0.39 & $(0.25 ; 0.60)$ & $<0.001$ \\
\hline
\end{tabular}

Schoenfeld residuals.

Global chi-squared test: $p=0.53$; detailed chi-squared test: latent CD4 trajectories: $p=0.09$; gender before 9 months on HAART: $p=0.64$; gender after 9 months on HAART: $p=0.89$; $B M I$ at HAART initiation: $p=0.67$.

\section{Immune reconstitution}

As it has been reported in other studies conducted in Southeast Asia, patients who start HAART were severely immunocompromised $[15,16,18]$. Without viral load measurements, WHO recommends to use CD4 reconstitution to assess the efficacy of treatment [26]. In this study, the median CD4 cells gain increases with time on HAART and this progression is comparable to the one observed in other lowincome countries [15,18-20,27,28].

As in other studies, the baseline CD4 cell count is a strong predictor of immune reconstitution, indicating that patients with higher baseline CD4 cell count achieve a better immune recovery $[29,30]$. In addition, our findings show that, overall, the CD4 cells increase faster for the most immunocompromised patients. This suggests that, in the long-term, the most immunocompromised patients, surviving the early phase on HAART, could restore their immunity as well as the other patients. Taking together, these results argue in favour of an earlier access to HAART and of an improvement in diagnosis and treatment of opportunistic infections during first months on treatment.

Several studies on large cohorts and long follow-up have failed to associate gender and immune reconstitution [31,32]. This study shows that women achieve a better immune recovery on HAART independently of the baseline CD4 cell count. This could be explained by better adherence for women, but we are unable to check this hypothesis because of the lack of adherence measurements. Although gender is generally not associated with adherence, comprehensive studies in Burkina Faso have shown a better use of health care facilities for women in the West of Africa as well as a better communication with health care workers on disease and treatment issues and argue in favour of better adherence behaviour among women [33-35]. Moreover, a higher long-term adherence to HAART among women has recently been shown in Senegal [36]. In this study, we have shown that women attend more regularly follow-up visits over time than men. This indicator, which could be used as a proxy of adherence, argues in favour of a better adherence for women. Another explanation could be that men who are frequently migrant worker do not adhere entirely to HAART because they could not refill on time [10-12]. In addition, a recent study in Thailand shows that women have more and earlier access to antiretroviral treatments [37]. Other factors like the stigma of HIV infection, family responsibilities, work or homophobia could impact on treatment access for men [38-40]. It has been shown that HIV-negative women had higher CD4 cell count than men in Africa [41]. However, it does not impact on 
HAART eligibility. Although our model is adjusted for baseline CD4 cell count, a physiological difference in CD4 counts could explain a steeper slope for women to return to their immunological equilibrium.

The latent trajectory analysis has identified two patterns of the CD4 evolution both for men and women. Overall, about a quarter of the patients followed a similar high CD4 trajectory, and about three quarters a lower one. About a third of women achieved a high CD4 trajectory whereas about a fifth of men achieved it. These results are in line with the mixed model.

The prevalence of the two latent trajectories reflects the distribution of baseline CD4 cell count. Indeed, patients with a low CD4 cell count at HAART initiation are more likely to follow a low CD4 trajectory. This explains why the prevalence of the first latent trajectory is high. Strength of this approach is that it describes the typical evolution of the CD4 cells in that cohort and it captures the effect of the low baseline CD4 count. The high membership probability observed even for patients with a low number of $\mathrm{CD} 4$ measurements allows us to assign patients to a unique latent trajectory with confidence. This is a new approach to explore different patterns of the CD4 evolution and it could be generalized to other longitudinal studies to reveal different patients' behaviour over time.

\section{Mortality}

Half of the deaths occur in the first four months after HAART initiation, showing a higher early mortality than the one generally observed in low-income countries. A recent scale-up of national antiretroviral therapy programmes in the Asia Pacific region shows that $50 \%$ of mortality occurs in the first 6 months of therapy [42]. High early mortality has also been reported in subSaharan Africa [43-46]. However, after 1 year on treatment, mortality is about $9 \%$ which is similar to other low-income countries $[15,19,28,47,48]$. A pooled analysis from 18 developing countries has assessed the risk of dying after 1 year at $5.8 \%$, which is about twice as low as in this cohort, as in other settings [49,50]. This early mortality could be explained by the advanced stage of infection and the low CD4 cell count of patients at enrollment, due to late presentation of patients [46]. As it has already been reported, poor adherence could be associated with increase in mortality $[48,51,52]$.

Mortality differs by patients' baseline characteristics such as CD4 cell count and BMI. These relationships have already been largely described both in low-income and high-income countries [15,18,28,44,45,47,53-55].

As shown in an observational cohort in South Africa, mortality is strongly associated with immune reconstitution during HAART [56]. Indeed, mortality differs by the two latent CD4 trajectories with a fivefold risk of death for the three quarters of patients following a low CD4 trajectory. Introducing these trajectories as a covariate of the Cox model provide a new way to explore the link between mortality and CD4 evolution on HAART, as it captures simultaneously the baseline and the reconstitution itself.

Our study also reveals a higher mortality among men. This result is also reported in other studies [57-63]. Men are more immunocompromised at HAART initiation which suggests a late presentation, as reported in South Africa [64]. Lower adherence and higher mobility among men are also mentioned by programme managers in Cambodia [58]. Here, the difference in mortality between men and women appears only after 9 months on HAART. It is important to highlight that this effect is independent of the latent CD4 trajectories and BMI. This result could point out sub-optimal care and treatment of clinical events occurring among men after the first year on treatment.

\section{Limitations of the study}

This study presents some limitations. First, we have no information about outcomes of patients lost to follow-up and transferred to Vientiane, which could bias the estimated immune recovery and mortality in the cohort. Adjusting mortality for loss to follow-up could correct the estimates, but due to the low lost to follow-up rate in this cohort, we did not use this method [65]. Then, because of technology availability and costs, viral load measurements were not available at that time. In addition, no data on adherence to antiretroviral was available.

\section{Conclusions}

This MSF programme where 913 patients initiated HAART with a very severe immuno-suppression reveals an important heterogeneity between patients and better outcomes for women. Indeed, a quarter of the patients present a high CD4 trajectory and women experience a better immune recovery and lower mortality than men. This study provides additional evidence for differences between men and women, once on HAART and, in particular, a difficulty for men to maintain a long-term compliance to treatment. Moreover, this study recommends that clinicians and healthcare providers have to pay special attention to men during treatment.

\section{Competing interests}

The authors declare that they have no competing interests.

\section{Authors' contributions}

MB designed the analyses, analyzed the data and interpreted the results, wrote the paper and submitted the final version. KS designed the study and collected the data. PP designed the study, interpreted the results and reviewed the manuscript. AHS designed the study and collected the data. LC designed the study, interpreted the results and reviewed the manuscript. AC designed the study, collected the data, interpreted the results and reviewed the manuscript. CP designed the study, interpreted the results and reviewed 
the manuscript. RE designed the analyses, interpreted the results and reviewed the manuscript. JFE coordinated the research, designed the analyses, interpreted the results and reviewed the manuscript. All authors read and approved the final manuscript.

\section{Acknowledgments}

We acknowledge Médecins Sans Frontières Switzerland (MSF-CH) and Institut de Recherche pour le Développement (IRD) for their financial support. We also thank the team of the Savannakhet Hospital, the different teams of MSF$\mathrm{CH}$ who succeeded in LAO PDR since 2003 and the MoH/CHAS to allow the carrying out of this study. Special thanks to Marlon Garcia for his help in the carrying out of the study and to Alvine Bissery for her contribution to the preliminary analysis.

\section{Author details}

${ }^{1}$ Epicentre, Paris, France. ${ }^{2}$ Ministry of Health/HIV Unit, Savannakhet Hospital, Savannakhet, Lao PDR. ${ }^{3}$ Mahosot Hospital, Vientiane, Lao PDR. ${ }^{4}$ Institut de la Francophonie pour la Médecine Tropicale, Vientiane, Lao PDR. ${ }^{5}$ Médecins Sans Frontières, Geneva, Switzerland. ${ }^{6}$ Ministry of Health - Centre for HIV, AIDS and STIs, Vientiane, Lao PDR. ${ }^{7}$ Hospices Civils de Lyon, Service de Biostatistique, Lyon F-69003, France. ${ }^{8}$ Université Lyon I, Villeurbanne F-69100, France. ${ }^{9}$ CNRS, UMR 5558, Laboratoire de Biométrie et Biologie Evolutive, Equipe Biostatistique Santé, Pierre-Bénite F-69310, France. ${ }^{10}$ UMI 233 TransVIHMI, Institut de Recherche pour le Développement, Université Montpellier 1, Montpellier, France.

Received: 28 February 2012 Accepted: 16 January 2013

Published: 22 January 2013

\section{References}

1. Akileswaran C, Lurie MN, Flanigan TP, Mayer KH: Lessons learned from use of highly active antiretroviral therapy in Africa. Clin Infect Dis 2005, 41:376-385.

2. Mocroft A, Ledergerber B, Katlama C, Kirk O, Reiss P, d' Arminio Monforte A, Knysz B, Dietrich M, Phillips AN, Lundgren JD: Decline in the AIDS and death rates in the EuroSIDA study: an observational study. Lancet 2003, 362:22-29.

3. Tassie JM, Szumilin E, Calmy A, Goemaere E: Highly active antiretroviral therapy in resource-poor settings: the experience of medecins sans frontieres. Aids 2003, 17:1995-1997.

4. Katzenstein D, Laga M, Moatti JP: The evaluation of the HIV/AIDS drug access initiatives in Cote d'Ivoire, Senegal and Uganda: how access to antiretroviral treatment can become feasible in Africa. Aids 2003, Suppl 3:S1-111.

5. Ivers LC, Kendrick D, Doucette K: Efficacy of antiretroviral therapy programs in resource-poor settings: a meta-analysis of the published literature. Clin Infect Dis 2005, 41:217-224.

6. Zhou J, Kumarasamy N, Ditangco R, Kamarulzaman A, Lee CK, Li PC, Paton NI, Phanuphak P, Pujari S, Vibhagool A, Wong WW, Zhang F, Chuah J, Frost KR, Cooper DA, Law MG: The TREAT Asia HIV observational database: baseline and retrospective data. J Acquir Immune Defic Syndr 2005, 38:174-179.

7. UN Joint Programme on HIV/AIDS: Global Report. Geneva: UNAIDS Report on the Global AIDS Epidemic; 2010. available at: http://www.unaids.org/ documents/20101123_globalreport_em.pdf. ISBN 978-92-9173-871-7.

8. Ruxrungtham K, Brown T, Phanuphak P: HIV/AIDS in Asia. Lancet 2004, 364:69-82.

9. National Committee for the Control of AIDS: Lao PDR UNGASS Country Progress Report 2010. Vientiane; 2010.

10. Sheridan S, Phimphachanh C, Chanlivong N, Manivong S, Khamsyvolsvong S, Lattanavong P, Sisouk T, Toledo C, Scherzer M, Toole M, van Griensven F: HIV prevalence and risk behaviour among men who have sex with men in Vientiane capital, Lao People's democratic republic, 2007. Aids 2009, 23:409-414.

11. Chulalongkorn University, Lao PDR's Center for HIV/AIDS/STI and Family Health International: Migration to Thailand and its Potential Contribution to an HIV Epidemic in Lao PDR. Vientiane: With support from the United States Agency for International Development (USAID); 2005.

12. Phimphachanh C, Sayabounthavong K, Oula R: Report on HIV prevalence study among migrant workers at 8 border provinces of Lao PDR. Center for HIV/AIDS/STI, Lao PDR; 2006.
13. Phimphachanh C, Sayabounthavong K: The HIV/AIDS/STI situation in Lao People's democratic republic. AIDS Educ Prev 2004, 16:91-99.

14. National Committee for the Control of AIDS: National strategic and action plan on HIV/AIDS/STI 2006-2010. Lao People's Democratic Republic: National Committee for the Control of AIDS; 2006.

15. Chasombat S, McConnell MS, Siangphoe U, Yuktanont P, Jirawattanapisal T, Fox K, Thanprasertsuk S, Mock PA, Ningsanond P, Lertpiriyasuwat C, Pinyopornpanich S: National expansion of antiretroviral treatment in Thailand, 2000-2007: program scale-up and patient outcomes. J Acquir Immune Defic Syndr 2009, 50:506-512.

16. Chaiwarith R, Salee P, Kotarathitithum W, Sirisanthana T, Supparatpinyo K: Long-term CD4 cell count recovery among Thai naive HIV-infected patients initiating HAART at low CD4 cell count. Curr HIV Res 2009, 7:340-345.

17. Fregonese F, Collins IJ, Jourdain G, Lecoeur S, Cressey TR, Ngo-Giang-Houng N, Banchongkit S, Chutanunta A, Techapornroong M, Lallemant M: Predictors of 5-year mortality in HIV-infected adults starting highly active antiretroviral therapy in Thailand. Journal of acquired immune deficiency syndromes (1999) 2012, 60:91-8.

18. Madec $Y$, Laureillard D, Pinoges L, Fernandez M, Prak N, Ngeth C, Moeung S, Song S, Balkan S, Ferradini L, Quillet C, Fontanet A: Response to highly active antiretroviral therapy among severely immuno-compromised HIV-infected patients in Cambodia. Aids 2007, 21:351-359.

19. Ferradini L, Laureillard D, Prak N, Ngeth C, Fernandez M, Pinoges L, Puertas G, Taburet AM, Ly N, Rouzioux C, Balkan S, Quillet C, Delfraissy JF: Positive outcomes of HAART at 24 months in HIV-infected patients in Cambodia. Aids 2007, 21:2293-2301.

20. Pujades-Rodríguez M, Schramm B, Som L, Nerrienet E, Narom P, Chanchhaya N, Ferradini L, Balkan S: Immunovirological outcomes and resistance patterns at 4 years of antiretroviral therapy use in HIVinfected patients in Cambodia. Tropical medicine \& international health: TM \& IH 2011, 16:205-13.

21. Skrondal A, Rabe-Hesketh S: Generalized latent variable modeling/: multilevel, longitudinal and structural equation models. Boca Raton, FL: Chapman \& Hall/CRC; 2004.

22. Rabe-Hesketh S, Skrondal A: Multilevel and longitudinal modeling using Stata. 2nd edition. College Station, TX: Stata Press; 2008.

23. Brinkhof MW, Dabis F, Myer L, Bangsberg DR, Boulle A, Nash D, Schechter M, Laurent C, Keiser O, May M, Sprinz E, Egger M, Anglaret X: Early loss of HIV-infected patients on potent antiretroviral therapy programmes in lower-income countries. Bull World Health Organ 2008, 86:559-567.

24. Rosen S, Fox MP, Gill CJ: Patient retention in antiretroviral therapy programs in sub-Saharan Africa: a systematic review. PLOS Med 2007, 4:e298.

25. Brinkhof MW, Pujades-Rodriguez M, Egger M: Mortality of patients lost to follow-up in antiretroviral treatment programmes in resource-limited settings: systematic review and meta-analysis. PLoS One 2009, 4:e5790

26. World Health Organization: Scaling up antiretroviral therapy in resourcelimited settings: treatment guidelines for a public health approach. Geneva: World Health Organization; 2003.

27. Toure S, Kouadio B, Seyler C, Traore M, Dakoury-Dogbo N, Duvignac J, Diakite N, Karcher S, Grundmann C, Marlink R, Dabis F, Anglaret X: Rapid scaling-up of antiretroviral therapy in 10,000 adults in cote d'Ivoire: 2-year outcomes and determinants. Aids 2008, 22:873-882.

28. Ferradini $L$, Jeannin A, Pinoges L, Izopet J, Odhiambo D, Mankhambo L, Karungi G, Szumilin E, Balandine S, Fedida G, Carrieri MP, Spire B, Ford N, Tassie JM, Guerin PJ, Brasher C: Scaling up of highly active antiretroviral therapy in a rural district of Malawi: an effectiveness assessment. Lancet 2006, 367:1335-1342.

29. De Beaudrap P, Etard JF, Diouf A, Ndiaye I, Gueye NF, Gueye PM, Sow PS, Mboup S, Ndoye I, Ecochard R, Eric D: Modeling CD4+ cell count increase over a six-year period in HIV-1-infected patients on highly active antiretroviral therapy in Senegal. Am J Trop Med Hyg 2009, 80:1047-1053.

30. Nash D, Katyal M, Brinkhof MW, Keiser O, May M, Hughes R, Dabis F, Wood R, Sprinz E, Schechter M, Egger M: Long-term immunologic response to antiretroviral therapy in low-income countries: a collaborative analysis of prospective studies. Aids 2008, 22:2291-2302.

31. Egger S, Petoumenos K, Kamarulzaman A, Hoy J, Sungkanuparph S, Chuah J, Falster K, Zhou J, Law MG: Long-term patterns in CD4 response are determined by an interaction between baseline CD4 cell count, viral load, and time: the Asia pacific HIV observational database (APHOD). J Acquir Immune Defic Syndr 2009, 50:513-520. 
32. Lawn SD, Myer L, Bekker LG, Wood R: CD4 Cell count recovery among HIV-infected patients with very advanced immunodeficiency commencing antiretroviral treatment in sub-Saharan Africa. BMC Infect Dis 2006, 6:59

33. Ammassari A, Trotta MP, Murri R, Castelli F, Narciso P, Noto P, Vecchiet J, D'Arminio Monforte A, Wu AW, Antinori A: Correlates and predictors of adherence to highly active antiretroviral therapy: overview of published literature. J Acquir Immune Defic Syndr 2002, 31(Suppl 3):S123-7.

34. Bila B, Egrot M: Gender asymmetry in healthcare-facility attendance of people living with HIV/AIDS in Burkina Faso. Soc Sci Med 2009, 69:854-861.

35. Desclaux A, Msellati P, Walentowitz S: Women, mothers and HIV care in resource-poor settings. Soc Sci Med 2009, 69:803-806.

36. Bastard M, Fall MB, Laniece I, Taverne B, Desclaux A, Ecochard R, Sow PS, Delaporte $E$, Etard JF: Revisiting long-term adherence to highly active antiretroviral therapy in Senegal using latent class analysis. J Acquir Immune Defic Syndr 2011, 57:55-61.

37. Le Coeur S, Collins IJ, Pannetier J, Lelievre E: Gender and access to HIV testing and antiretroviral treatments in Thailand: why do women have more and earlier access? Soc Sci Med 2009, 69:846-853.

38. Portelli MS, Tenni B, Kounnavong S, Chanthivilay P: Barriers to and facilitators of adherence to antiretroviral therapy among people living with HIV in Lao PDR: a qualitative study. Asia-Pacific: Journal of public health/Asia-Pacific Academic Consortium for Public Health; 2012

39. Remien RH, Chowdhury J, Mokhbat JE, Soliman C, Adawy ME, El-Sadr W: Gender and care: access to HIV testing, care, and treatment. J Acquir Immune Defic Syndr 2009, 51(Suppl 3):S106-10.

40. Braitstein P, Boulle A, Nash D, Brinkhof MW, Dabis F, Laurent C, Schechter M, Tuboi SH, Sprinz E, Miotti P, Hosseinipour M, May M, Egger M, Bangsberg DR, Low N: Gender and the use of antiretroviral treatment in resourceconstrained settings: findings from a multicenter collaboration. J Womens Health (Larchmt) 2008, 17:47-55.

41. Mair C, Hawes SE, Agne HD, Sow PS, N'Doye I, Manhart LE, Fu PL, Gottlieb GS, Kiviat NB: Factors associated with CD4 lymphocyte counts in HIVnegative Senegalese individuals. Clin Exp Immunol 2008, 151:432-440.

42. Srikantiah P, Ghidinelli M, Bachani D, Chasombat S, Daoni E, Mustikawati DE, Nhan do T, Pathak LR, San KO, Vun MC, Zhang F, Lo YR, Narain JP: Scale-up of national antiretroviral therapy programs: progress and challenges in the Asia pacific region. Aids 2010, 24(Suppl 3):S62-71.

43. Johannessen A, Naman E, Ngowi BJ, Sandvik L, Matee Ml, Aglen HE, Gundersen SG, Bruun JN: Predictors of mortality in HIV-infected patients starting antiretroviral therapy in a rural hospital in Tanzania. BMC Infect Dis 2008, 8:52.

44. Sieleunou I, Souleymanou M, Schonenberger AM, Menten J, Boelaert M: Determinants of survival in AIDS patients on antiretroviral therapy in a rural centre in the Far-north province Cameroon. Trop Med Int Health 2009, 14:36-43.

45. Zachariah R, Fitzgerald M, Massaquoi M, Pasulani O, Arnould L, Makombe S, Harries AD: Risk factors for high early mortality in patients on antiretroviral treatment in a rural district of Malawi. Aids 2006, 20:2355-2360.

46. Lawn SD, Harries AD, Anglaret X, Myer L, Wood R: Early mortality among adults accessing antiretroviral treatment programmes in sub-Saharan Africa. Aids 2008, 22:1897-1908.

47. Etard JF, Ndiaye I, Thierry-Mieg M, Gueye NF, Gueye PM, Laniece I, Dieng AB, Diouf A, Laurent C, Mboup S, Sow PS, Delaporte E: Mortality and causes of death in adults receiving highly active antiretroviral therapy in Senegal: a 7-year cohort study. Aids 2006, 20:1181-1189.

48. Stringer JS, Zulu I, Levy J, Stringer EM, Mwango A, Chi BH, Mtonga V, Reid S, Cantrell RA, Bulterys M, Saag MS, Marlink RG, Mwinga A, Ellerbrock TV, Sinkala M: Rapid scale-up of antiretroviral therapy at primary care sites in Zambia: feasibility and early outcomes. Jama 2006, 296:782-793.

49. Dabis F, Balestre E, Braitstein P, Miotti P, Brinkhof WG, Schneider M, Schechter M, Laurent C, Boulle A, Kabugo C, Capkun G, Seyler C, Mclntyre J, Sprinz E, Bangsberg D, Van der Borght S, Egger M: Cohort profile: antiretroviral therapy in lower income countries (ART-LINC): international collaboration of treatment cohorts. Int J Epidemiol 2005, 34:979-986.

50. Braitstein P, Brinkhof MW, Dabis F, Schechter M, Boulle A, Miotti P, Wood R, Laurent C, Sprinz E, Seyler C, Bangsberg DR, Balestre E, Sterne JA, May M, Egger M: Mortality of HIV-1-infected patients in the first year of antiretroviral therapy: comparison between low-income and high-income countries. Lancet 2006, 367:817-824.
51. Abaasa AM, Todd J, Ekoru K, Kalyango JN, Levin J, Odeke E, Karamagi CA: Good adherence to HAART and improved survival in a community HIV/ AIDS treatment and care programme: the experience of the AIDS support organization (TASO), Kampala Uganda. BMC Health Serv Res 2008, $8: 241$

52. Nachega JB, Hislop M, Dowdy DW, Lo M, Omer SB, Regensberg L, Chaisson RE, Maartens G: Adherence to highly active antiretroviral therapy assessed by pharmacy claims predicts survival in HIV-infected south African adults. J Acquir Immune Defic Syndr 2006, 43:78-84.

53. Srasuebkul P, Lim PL, Lee MP, Kumarasamy N, Zhou J, Sirisanthana T, Li PC Kamarulzaman A, Oka S, Phanuphak P, Vonthanak S, Merati TP, Chen YM Sungkanuparph S, Tau G, Zhang F, Lee CK, Ditangco R, Pujari S, Choi JY, Smith J, Law MG: Short-term clinical disease progression in HIV-infected patients receiving combination antiretroviral therapy: results from the TREAT Asia HIV observational database. Clin Infect Dis 2009, 48:940-950.

54. May M, Sterne JA, Sabin C, Costagliola D, Justice AC, Thiebaut R, Gill J, Phillips A, Reiss P, Hogg R, Ledergerber B, D'Arminio Monforte A, Schmeisser N, Staszewski S, Egger M: Prognosis of HIV-1-infected patients up to 5 years after initiation of HAART: collaborative analysis of prospective studies. Aids 2007, 21:1185-1197.

55. Moh R, Danel C, Messou E, Ouassa T, Gabillard D, Anzian A, Abo Y, Salamon R, Bissagnene E, Seyler C, Eholie S, Anglaret X: Incidence and determinants of mortality and morbidity following early antiretroviral therapy initiation in HIV-infected adults in west Africa. Aids 2007, 21:2483-2491.

56. Lawn SD, Little F, Bekker LG, Kaplan R, Campbel E, Orrell C, Wood R: Changing mortality risk associated with CD4 cell response to antiretroviral therapy in south Africa. Aids 2009, 23:335-342.

57. Chen SC, Yu JK, Harries AD, Bong CN, Kolola-Dzimadzi R, Tok TS, King CC, Wang JD: Increased mortality of male adults with AIDS related to poor compliance to antiretroviral therapy in Malawi. Trop Med Int Health 2008 , 13:513-519.

58. Thai S, Koole O, Un P, Ros S, De Munter P, Van Damme W, Jacques G, Colebunders $R$, Lynen L: Five-year experience with scaling-up access to antiretroviral treatment in an HIV care programme in Cambodia. Trop Med Int Health 2009, 14:1048-1058.

59. Zachariah R, Harries K, Moses M, Manzi M, Line A, Mwagomba B, Harries AD: Very early mortality in patients starting antiretroviral treatment at primary health centres in rural Malawi. Trop Med Int Health 2009, 14:713-721.

60. DeSilva MB, Merry SP, Fischer PR, Rohrer JE, Isichei CO, Cha SS: Youth, unemployment, and male gender predict mortality in AIDS patients started on HAART in Nigeria. AIDS Care 2009, 21:70-77.

61. Calmy A, Pinoges L, Szumilin E, Zachariah R, Ford N, Ferradini L: Generic fixed-dose combination antiretroviral treatment in resource-poor settings: multicentric observational cohort. Aids 2006, 20:1163-1169.

62. Hawkins C, Chalamilla G, Okuma J, Spiegelman D, Hertzmark E, Aris E, Ewald T, Mugusi F, Mtasiwa D, Fawzi W: Gender differences in antiretroviral treatment outcomes among HIV-infected adults in Dar es salaam, Tanzania. Aids 2011, 25. Ahead of print.

63. Cornell M, Schomaker M, Garone DB, Giddy J, Hoffmann CJ, Lessells R, Maskew M, Prozesky H, Wood R, Johnson LF, Egger M, Boulle A, Myer L: Gender differences in survival among adult patients starting antiretroviral therapy in south Africa: a multicentre cohort study. PLOS medicine 2012, 9:e1001304.

64. Cornell M, Myer L, Kaplan R, Bekker LG, Wood R: The impact of gender and income on survival and retention in a south African antiretroviral therapy programme. Trop Med Int Health 2009, 14:722-731.

65. Brinkhof MWG, Spycher BD, Yiannoutsos C, Weigel R, Wood R, Messou E, Boulle A, Egger M, Sterne JAC, for the International epidemiological Database to Evaluate A: Adjusting mortality for loss to follow-Up: analysis of five ART programmes in Sub-Saharan Africa. PLoS One 2010, 5:e14149.

\section{doi:10.1186/1471-2334-13-27}

Cite this article as: Bastard et al: Women experience a better long-term immune recovery and a better survival on HAART in Lao People's Democratic Republic. BMC Infectious Diseases 2013 13:27. 